Atmos. Chem. Phys., 18, 10123-10132, 2018

https://doi.org/10.5194/acp-18-10123-2018

(C) Author(s) 2018. This work is distributed under

the Creative Commons Attribution 4.0 License.

\title{
Particle acidity and sulfate production during severe haze events in China cannot be reliably inferred by assuming a mixture of inorganic salts
}

\author{
Gehui Wang ${ }^{1,2,3}$, Fang Zhang ${ }^{4,5}$, Jianfei Peng ${ }^{5,6}$, Lian Duan ${ }^{5,7}$, Yuemeng $\mathbf{J i}^{5,8}$, Wilmarie Marrero-Ortiz ${ }^{5}$, \\ Jiayuan Wang ${ }^{2}$, Jianjun $\mathbf{L i}^{2}$, Can Wu${ }^{2}$, Cong Cao ${ }^{2}$, Yuan Wang ${ }^{9}$, Jun Zheng ${ }^{10}$, Jeremiah Secrest ${ }^{5}$, Yixin $\mathbf{L i}^{5}$, \\ Yuying Wang ${ }^{4,5}$, Hong $\mathbf{L i}^{11}$, Na $\mathbf{~ L i}^{5,12}$, and Renyi Zhang ${ }^{5,6}$ \\ ${ }^{1}$ Key Laboratory of Geographic Information Science of the Ministry of Education, School of Geographic Sciences, \\ East China Normal University, Shanghai 200241, China \\ ${ }^{2}$ State Key Laboratory of Loess and Quaternary Geology, Institute of Earth Environment, \\ Chinese Academy of Sciences, Xi'an 710061, China \\ ${ }^{3}$ Center for Excellence in Regional Atmospheric Environment, Institute of Urban Environment, \\ Chinese Academy of Science, Xiamen 361021, China \\ ${ }^{4}$ College of Global Change and Earth System Science, Beijing Normal University, Beijing 100875, China \\ ${ }^{5}$ Departments of Atmospheric Sciences and Chemistry, Texas A\&M University, College Station, TX, 77843, USA \\ ${ }^{6}$ State Key Joint Laboratory of Environmental Simulation and Pollution Control, College of Environmental Sciences \\ and Engineering, Peking University, Beijing 100871, China \\ ${ }^{7}$ State Environmental Protection Key Lab of Environmental Risk Assessment and control on Chemical Processes, \\ East China University of Science and Technology, Shanghai 200237, China \\ ${ }^{8}$ School of Environmental Science and Engineering, Institute of Environmental Health and Pollution, Control, \\ Guangdong University of Technology, Guangzhou 510006, China \\ ${ }^{9}$ Jet Propulsion Laboratory, California Institute of Technology, Pasadena, CA 91125, USA \\ ${ }^{10}$ Jiangsu Key Laboratory of Atmospheric Environment Monitoring and Pollution Control, \\ Nanjing University of Information Science \& Technology, Nanjing 210044, China \\ ${ }^{11}$ State Key Laboratory of Environmental Criteria and Risk Assessment, Chinese Research Academy of \\ Environmental Sciences, Beijing 100012, China \\ ${ }^{12}$ Key Laboratory of Songliao Aquatic Environment, Jilin Jianzhu University, Changchun, 130118, China
}

Correspondence: Gehui Wang (ghwang@geo.ecnu.edu.cn,wanggh@ieecas.cn) and Renyi Zhang (renyi-zhang@tamu.edu)

Received: 19 February 2018 - Discussion started: 22 February 2018

Revised: 29 May 2018 - Accepted: 2 July 2018 - Published: 17 July 2018

\begin{abstract}
Atmospheric measurements showed rapid sulfate formation during severe haze episodes in China, with fine particulate matter (PM) consisting of a multi-component mixture that is dominated by organic species. Several recent studies using the thermodynamic model estimated the particle acidity and sulfate production rate, by treating the PM exclusively as a mixture of inorganic salts dominated by ammonium sulfate and neglecting the effects of organic compounds. Noticeably, the estimated $\mathrm{pH}$ and sulfate formation rate during pollution periods in China were highly conflicting among the previous studies. Here we show that a particle
\end{abstract}

mixture of inorganic salts adopted by the previous studies does not represent a suitable model system and that the acidity and sulfate formation cannot be reliably inferred without accounting for the effects of multi-aerosol compositions during severe haze events in China. Our laboratory experiments show that $\mathrm{SO}_{2}$ oxidation by $\mathrm{NO}_{2}$ with $\mathrm{NH}_{3}$ neutralization on fine aerosols is dependent on the particle hygroscopicity, phase-state, and acidity. Ammonium sulfate and oxalic acid seed particles exposed to vapors of $\mathrm{SO}_{2}, \mathrm{NO}_{2}$, and $\mathrm{NH}_{3}$ at high relative humidity $(\mathrm{RH})$ exhibit distinct size growth and sulfate formation. Aqueous ammonium sulfate particles ex- 
hibit little sulfate production, in contrast to aqueous oxalic acid particles with significant sulfate production. Our field measurements demonstrate significant contribution of watersoluble organic matter to fine PM in China and indicate that the use of oxalic acid in laboratory experiments is representative of ambient organic dominant aerosols. While the particle acidity cannot be accurately determined from field measurements or calculated using the thermodynamic model, our results reveal that the $\mathrm{pH}$ value of ambient organics-dominated aerosols is sufficiently high to promote efficient $\mathrm{SO}_{2}$ oxidation by $\mathrm{NO}_{2}$ with $\mathrm{NH}_{3}$ neutralization under polluted conditions in China.

\section{Introduction}

Atmospheric measurements have demonstrated rapid sulfate production during severe haze events in China (Guo et al., 2014; Wang et al., 2014, 2016; Zhang et al., 2015; Cheng et al., 2016). For example, Wang et al. (2016) showed that, during pollution episodes in $\mathrm{Xi}$ ' an, the $\mathrm{SO}_{4}^{2-}$ mass concentration increased markedly from less than 10 , from 10 to 20 , and to greater than $20 \mu \mathrm{g} \mathrm{m}^{-3}$, with the corresponding increases in the mean $\mathrm{PM}_{2.5}$ mass concentrations from 43 , 139 , to $250 \mu \mathrm{g} \mathrm{m}^{-3}$ from clean, transition, to polluted periods, respectively. Among the $\mathrm{PM}_{2.5}$ species in Xi' an, organic matter $(\mathrm{OM})$, nitrate $\left(\mathrm{NO}_{3}^{-}\right)$, and $\mathrm{SO}_{4}^{2-}$ were most abundant, with the mass fractions of 55, 14 , and $14 \%$, respectively, during the polluted period. In addition, the work of Wang et al. (2016) demonstrated that the molar ratio of $\mathrm{SO}_{4}^{2-}$ to $\mathrm{SO}_{2}$, which reflects sulfur partitioning between the particle and gas phases, exhibited an exponential increase with relative humidity $(\mathrm{RH})$, with the values of less than 0.1 at $\mathrm{RH}<20 \%$ to 1.1 at $\mathrm{RH}>90 \%$ in Xi' an. Similar evolutions in $\mathrm{SO}_{4}^{2-}$ mass concentrations and the molar ratio of $\mathrm{SO}_{4}^{2-}$ to $\mathrm{SO}_{2}$ were shown during the pollution development in Beijing (Sun et al., 2013; Wang et al., 2014, 2016). The rapid sulfate formation measured in China could not be explained by current atmospheric models and suggested missing sulfur oxidation mechanisms (Wang et al., 2014). Typically, high sulfate levels during haze events in China occurred concurrently with elevated $\mathrm{RH}, \mathrm{NO}_{x}$, and $\mathrm{NH}_{3}$ (Wang et al., 2014, 2016; Zhang et al., 2015), implicating an aqueous sulfur oxidation pathway. On the basis of complementary field and experimental measurements, Wang et al. (2016) concluded that the aqueous oxidation of $\mathrm{SO}_{2}$ by $\mathrm{NO}_{2}$ is key to efficient sulfate formation, but is only feasible under two atmospheric conditions, i.e., on fine aerosols with high $\mathrm{RH}$ and $\mathrm{NH}_{3}$ neutralization or under cloud conditions.

Several recent studies estimated the particle acidity and aqueous sulfate production during severe haze events in China using the thermodynamic model (Cheng et al., 2016; Guo et al., 2017a; M. Liu et al., 2017). For example, Cheng et al. (2016) estimated a $\mathrm{pH}$ range of 5.4 to 6.2 using a thermodynamic model (ISORROPIA-II) in Beijing. On the basis of their estimated $\mathrm{pH}$ and the previous experimental rates of $\mathrm{SO}_{2}$ oxidation by $\mathrm{NO}_{2}$ and the Henry's Law constants for sulfur dioxide $\left(\mathrm{SO}_{2}\right)$, bisulfite $\left(\mathrm{HSO}_{3}^{-}\right)$, and sulfite $\left(\mathrm{SO}_{3}^{2-}\right)$ from the literature (Lee and Schwartz, 1983; Clifton et al., 1988; Seinfeld and Pandis, 2006), the authors derived a sulfate production rate and concluded that reactive nitrogen chemistry in aerosol water explained the sulfate formation during polluted periods in Beijing. In contrast, other recent studies by Guo et al. (2017a) and M. Liu et al. (2017) adopted a similar method to Cheng et al. (2016), but reported significantly different values of $\mathrm{pH}$ and the sulfate formation rates by the aqueous $\mathrm{SO}_{2}$ oxidation by $\mathrm{NO}_{2}$ in China. Those two later studies determined a $\mathrm{pH}$ range of 3.0-4.9 and suggested that fine particles were moderately acidic and the aqueous $\mathrm{SO}_{2}$ oxidation by $\mathrm{NO}_{2}$ was unimportant during severe wintertime haze periods in China.

In this article, we conducted laboratory measurements of the hygroscopicity for oxalic acid particles and particle growth of ammonium sulfate particles upon exposure to $\mathrm{SO}_{2}$, $\mathrm{NO}_{2}$, and $\mathrm{NH}_{3}$ at high $\mathrm{RH}$ conditions, in order to evaluate the dominant factors regulating the aqueous oxidation of $\mathrm{SO}_{2}$ by $\mathrm{NO}_{2}$. In addition, field measurements of chemical compositions of water-soluble fraction for fine PM (including oxalic acid) in Beijing, Hebei Province, and Xi' an were performed during the winter haze episodes, showing significantly enriched water-soluble organic matter (WSOM). The implications for the multi-aerosol chemical compositions on the $\mathrm{pH}$ value and sulfate production during winter pollution periods in China are discussed.

\section{Methods}

\subsection{Aqueous phase oxidation of $\mathrm{SO}_{2}$ by $\mathrm{NO}_{2}$ in an environmental chamber}

The experimental method using the environmental chamber has been discussed elsewhere (Wang et al., 2016), and here we only provide a brief description. The aqueous $\mathrm{SO}_{2}$ oxidation experiments was conducted by exposing size-selected $\left(\mathrm{NH}_{4}\right)_{2} \mathrm{SO}_{4}$ seed particles to different levels of $\mathrm{SO}_{2}, \mathrm{NO}_{2}$, and $\mathrm{NH}_{3}$ at variable $\mathrm{RH}$ conditions in a $1 \mathrm{~m}^{3}$ Teflon reaction chamber covered with aluminum foil. A differential mobility analyzer (DMA) equipped with a condensation particle counter (CPC) was used to measure the particle growth in diameter, in order to determine sulfate formation on seeded particles (Wang et al., 2016). 


\subsection{Measurement of hygroscopic growth factor of oxalic acid}

Hygroscopic growth factor (HGF) of oxalic acid was measured according to the method previously discussed (Khalizov et al., 2009; Pagels et al., 2009). Briefly, a hygroscopicity tandem differential mobility analyzer (HTDMA) coupled to a condensation particle counter (CPC, TSI 3762) was used for the HGF measurement. Size-selected oxalic acid particles with the dry diameter of $100 \mathrm{~nm}$ were exposed to increasing $\mathrm{RH}$ from 8 to $92 \%$ with a step range from 1 to $10 \%$. HGF is defined as the ratio of oxalic acid particle diameter $\left(D_{\mathrm{p}}\right)$ measured by the second DMA at an elevated RH to the initial diameter $\left(D_{0}=100 \mathrm{~nm}\right)$ of the particles selected by the first DMA at the dry conditions of $\mathrm{RH}=8 \%$ (Peng et al., 2016).

\subsection{Chemical composition of $\mathbf{P M}_{2.5}$ in Beijing, Hebei Province, and Xi'an, China}

$\mathrm{PM}_{2.5}$ samples were collected onto pre-baked $\left(450^{\circ} \mathrm{C}\right.$ for $6 \mathrm{~h})$ quartz fiber filter by using a high-volume air sampler with an airflow rate of $1.03 \mathrm{~m}^{3} \mathrm{~min}^{-1}$. The sample collection in Xi' an was performed on the roof of a three-story building in the urban center with a $1 \mathrm{~h}$ interval for each sample during the winter of 2012 (Wang et al., 2016). The sample collection in Beijing was conducted during the winter of 2016 on the roof of a four-story building on the campus of China Research Academy of Environmental Sciences, which is located at the northern part of Beijing. The $\mathrm{PM}_{2.5}$ samples in Hebei Province were collected during the winter of 2016 on the roof of a three-story building on the campus of the Institute of Hydrology and Environmental Geology, which is located in Zhengding County of Hebei Province. Both sample collections in Beijing and Hebei Province were performed on a day/night basis. After collection, all samples were sealed individually in an aluminum foil bag and stored in a freezer below $-18^{\circ} \mathrm{C}$ prior to analysis. During the sampling periods temperatures were $-6.0 \pm 4.0^{\circ} \mathrm{C}$ $\left(-15-1.0^{\circ} \mathrm{C}\right),-4.0 \pm 3.0^{\circ} \mathrm{C}\left(-12-2.0^{\circ} \mathrm{C}\right)$, and $1.6 \pm 4.4^{\circ} \mathrm{C}$ $\left(-5.4-15^{\circ} \mathrm{C}\right)$ in Beijing, Hebei Province, and Xi' an, respectively, while relative humidity at the three sites $(\mathrm{RH})$ were $37 \pm 18 \%(16-87 \%), 46 \pm 21 \%(16-87 \%)$, and $59 \pm 21 \%$ (15-95\%), respectively. Previous observations showed that coal combustion, biomass burnings and vehicle exhausts are the three major sources of $\mathrm{PM}_{2.5}$ during winter in North China including Beijing, Hebei Province, and $\mathrm{Xi}$ ' an ( $\mathrm{Li}$ et al., 2016; Zhang et al., 2015).

The detailed procedures for the analysis of inorganic ions and water-soluble organic matter (WSOM) in aerosols have been reported elsewhere (Wang et al., 2017; G. Wang et al., 2009, 2010). Briefly, one part of the filter sample (area about $5 \mathrm{~cm}^{2}$ ) was divided into several pieces, extracted with Mili-Q pure water, and determined for WSOM and inorganic ions by using Shimadzu TOC-L CPH analyzer and
Dionex-600 ion chromatography, respectively. Oxalic acid in $\mathrm{PM}_{2.5}$ was analyzed according to Wang et al. (2002) and Cheng et al. (2015). One part of the filter sample was extracted with Milli-Q water, concentrated to dryness, and reacted with $14 \% \mathrm{BF} 3 / \mathrm{butanol}$ at $100^{\circ} \mathrm{C}$ for $1 \mathrm{~h}$. After the reaction, the derivatized sample was extracted with hexane for three times and concentrated into $1 \mathrm{~mL}$. Oxalic acid in the samples was identified by gas chromatography-mass spectrometry (GC-MS) and quantified by gas chromatography (Agilent GC7890A).

\section{Results}

\subsection{Aqueous oxidation of $\mathrm{SO}_{2}$ by $\mathrm{NO}_{2}$ with $\mathrm{NH}_{3}$ neutralization}

We first evaluated the factors controlling the aqueous phase oxidation of $\mathrm{SO}_{2}$ by $\mathrm{NO}_{2}$ using the environmental chamber method. The evolution in the size of ammonium sulfate particles after exposure to $\mathrm{SO}_{2}, \mathrm{NO}_{2}$, and $\mathrm{NH}_{3}$ at different $\mathrm{RH}$ and $\mathrm{SO}_{2}$ levels is shown in Fig. 1. In our experiments, monodisperse particles with the initial dry particle size ranging from 50 to $70 \mathrm{~nm}$ were selected for the exposure, and two different $\mathrm{SO}_{2}$ concentrations ( 37.5 and 375 parts per billions or ppb) were used. RH was maintained at a level of 80 $98 \%$, above the deliquescence point (79\%) of ammonium sulfate (Qiu and Zhang, 2013) to ensure aqueous particles. As is shown in Fig. 1, the size of $\left(\mathrm{NH}_{4}\right)_{2} \mathrm{SO}_{4}$ particles remains nearly invariant (within the experimental uncertainty) after exposure to $\mathrm{SO}_{2}, \mathrm{NO}_{2}$, and $\mathrm{NH}_{3}$. A 10 -fold increase in the $\mathrm{SO}_{2}$ concentration has little effect on the growth of $\left(\mathrm{NH}_{4}\right)_{2} \mathrm{SO}_{4}$ particles. These results illustrate that sulfate production is insignificant and $\mathrm{SO}_{2}$ cannot be efficiently oxidized by $\mathrm{NO}_{2}$ in the presence of $\mathrm{NH}_{3}$ on aqueous ammonium sulfate particles. The measurement of negligible growth for $\left(\mathrm{NH}_{4}\right)_{2} \mathrm{SO}_{4}$ particles exposed to $\mathrm{SO}_{2}, \mathrm{NO}_{2}$, and $\mathrm{NH}_{3}$ at high $\mathrm{RH}$ is in contrast to the previous work by Wang et al. (2016), which showed large size growth and significant sulfate production for oxalic acid particles with $\mathrm{NH}_{3}$ neutralization and under high RH conditions (see the black triangles in Fig. 1).

To gain an insight into such a difference in the size growth between $\left(\mathrm{NH}_{4}\right)_{2} \mathrm{SO}_{4}$ and oxalic acid particles, we measured the hygroscopic growth of oxalic acid particles. Figure 2 displays the measured hygroscopic growth factor (HGF) of oxalic acid, showing an exponential increase with an increase in $\mathrm{RH}$. The measured HGF value is close to unity at $\mathrm{RH}<40 \%$ and increases from 1.1 at $\mathrm{RH}=60 \%$ to 1.5 at $\mathrm{RH}=90 \%$. Our measured HGF for oxalic acid is consistent with the previous studies by Prenni et al. (2001) and Mikhailov et al. (2009); all of which were measured by using a hygroscopicity tandem differential mobility analyzer (HTDMA) system. In contrast, another earlier experimental study showed little growth for oxalic acid particles under high RH conditions by using an electrodynamic balance (EDB) system 


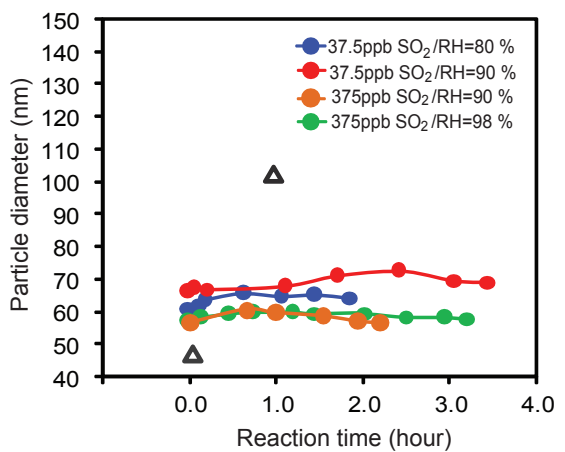

Figure 1. Size evolution of ammonium sulfate (circle dots) and oxalic acid (black triangles) particles after exposure to $\mathrm{SO}_{2}, \mathrm{NO}_{2}$, and $\mathrm{NH}_{3}$ at different $\mathrm{RH}$ levels. Variations in mobility diameter $\left(D_{\mathrm{p}}\right)$ of the particles as a function of reaction time. The symbols with different colors denote measurements with exposure to different $\mathrm{SO}_{2}$, $\mathrm{NO}_{2}$, and $\mathrm{NH}_{3}$ concentrations and $\mathrm{RH}$ levels. For the ammonium sulfate particles exposure experiment, two levels of $\mathrm{SO}_{2}$ were used, which are 37.5 and $375 \mathrm{ppb}$, respectively, while the $\mathrm{NO}_{2}$ concentration is $375 \mathrm{ppb}$, and the $\mathrm{NH}_{3}$ concentration is $500 \mathrm{ppb}$. For the oxalic acid particles exposure experiment, the $\mathrm{SO}_{2}$ concentration is $250 \mathrm{ppb}$, the $\mathrm{NO}_{2}$ concentration is $250 \mathrm{ppb}$, and the $\mathrm{NH}_{3}$ concentration is $1 \mathrm{ppm}$ (The data of oxalic acid growth are cited from the previous study by Wang et al., 2016).

(Peng et al., 2001). The different HGF measured for oxalic acid is most likely due to the different accuracies of the two types of methods for the hygroscopicity measurement. The measurements of HGF also provide information on the particle phase-state. As evident from Fig. 2, oxalic acid particles mainly exist in a non-aqueous phase at $\mathrm{RH}<40 \%$ but in the aqueous phase at $\mathrm{RH}>60 \%$.

Our present experiments of aqueous oxidation of $\mathrm{SO}_{2}$ by $\mathrm{NO}_{2}$ were performed under similar conditions as those by Wang et al. (2016), i.e., with comparable concentrations for $\mathrm{SO}_{2}, \mathrm{NO}_{2}$, and $\mathrm{NH}_{3}$ and in the same phase-state (aqueous) for the particles. In contrast, the particle acidity is clearly distinct between the two studies. Our present experiment is characterized by a lower $\mathrm{pH}$ value, as ammonium sulfate is rather acidic. For example, the $\mathrm{pH}$ value of $0.1 \mathrm{M}\left(\mathrm{NH}_{4}\right)_{2} \mathrm{SO}_{4}$ solution is 5.5. The overall aqueous reaction between $\mathrm{SO}_{2}$ and $\mathrm{NO}_{2}$ in the presence of $\mathrm{NH}_{3}$ is suggested as the following (Wang et al., 2016),

$$
\begin{array}{r}
2 \mathrm{NH}_{3}(\mathrm{~g})+\mathrm{SO}_{2}(\mathrm{~g})+2 \mathrm{NO}_{2}(\mathrm{~g})+2 \mathrm{H}_{2} \mathrm{O}(\mathrm{aq}) \\
\rightarrow 2 \mathrm{NH}_{4}^{+}(\mathrm{aq})+\mathrm{SO}_{4}^{2-}(\mathrm{aq})+2 \mathrm{HONO}(\mathrm{g}) .
\end{array}
$$

As the solubility of $\mathrm{SO}_{2}$ decreases markedly with increasing particle acidity (Seinfeld and Pandis, 2006; Zhang et al., 2015), the heterogeneous reaction between $\mathrm{SO}_{2}$ and $\mathrm{NO}_{2}$ is prohibited on acidic $\left(\mathrm{NH}_{4}\right)_{2} \mathrm{SO}_{4}$ particles. In contrast, under the experimental conditions by Wang et al. (2016), the heterogeneous reaction between oxalic acid and $\mathrm{NH}_{3}$ occurred on aqueous particles in the presence of $\mathrm{NH}_{3}$, yielding ammo-

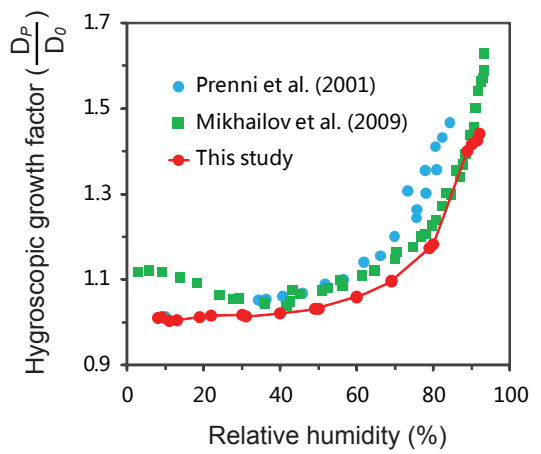

Figure 2. Measured hygroscopic growth factor (HGF) of oxalic acid particles at different $\mathrm{RH}$ conditions. $D_{\mathrm{p}}$ is the particle diameter at an elevated $\mathrm{RH}$, and $D_{0}(100 \mathrm{~nm})$ is the initial diameter of oxalic acid particles at $\mathrm{RH}=8 \%$.

nium oxalate. The ammonium oxalate is expected to be less acidic than ammonium sulfate, because for a bulk solution the $\mathrm{pH}$ value of $0.1 \mathrm{M}$ ammonium oxalate is 6.5 and one unit higher than that of ammonium sulfate. As a result, $\mathrm{SO}_{2}$ readily dissolves into aqueous ammonium oxalate particles and is oxidized by $\mathrm{NO}_{2}$ into $\mathrm{SO}_{4}^{2-}$, which is consequently neutralized by $\mathrm{NH}_{3}$ to produce $\left(\mathrm{NH}_{4}\right)_{2} \mathrm{SO}_{4}$. The resulting aqueous ammonium oxalate/ $\left(\mathrm{NH}_{4}\right)_{2} \mathrm{SO}_{4}$ particles, which is internally mixed, exhibit a lower acidity than that of pure $\left(\mathrm{NH}_{4}\right)_{2} \mathrm{SO}_{4}$ particles, responsible for a significant growth in the dry particle size and sulfate formation for the previous experiments by Wang et al. (2016).

Hence, the experimental studies of our present work and that by Wang et al. (2016) reveal that sulfate production on fine particles is dependent on several factors, including the particle hygroscopicity, phase-state, acidity, and $\mathrm{RH}$, in addition to the gaseous concentrations of $\mathrm{SO}_{2}, \mathrm{NO}_{2}$, and $\mathrm{NH}_{3}$. These experimental results indicate that the acidity and sulfate formation are distinct for organic seed and ammonium sulfate seed particles. While oxidation of $\mathrm{SO}_{2}$ by $\mathrm{NO}_{2}$ on aqueous $\left(\mathrm{NH}_{4}\right)_{2} \mathrm{SO}_{4}$ particles does not represent a viable mechanism because of a higher acidity, significant sulfate production occurs on oxalic acid particles because of a lower acidity.

\subsection{Field measurements of WSOM in China}

Atmospheric measurements have shown that the occurrence of severe haze episodes in China is accompanied with high $\mathrm{RH}$ conditions and $\mathrm{PM}_{2.5}$ particles consist of large amounts of secondary organic and inorganic compounds. We present additional field measurements of the chemical composition of $\mathrm{PM}_{2.5}$ in Beijing, Hebei Province, and Xi'an. Figure 3 shows that the wintertime $\mathrm{PM}_{2.5}$ samples collected at the three locations. It is evident that WSOM is considerably enriched and their concentrations are comparable to those of the total inorganic ions (Fig. $3 \mathrm{a}$ and b). For example, the 

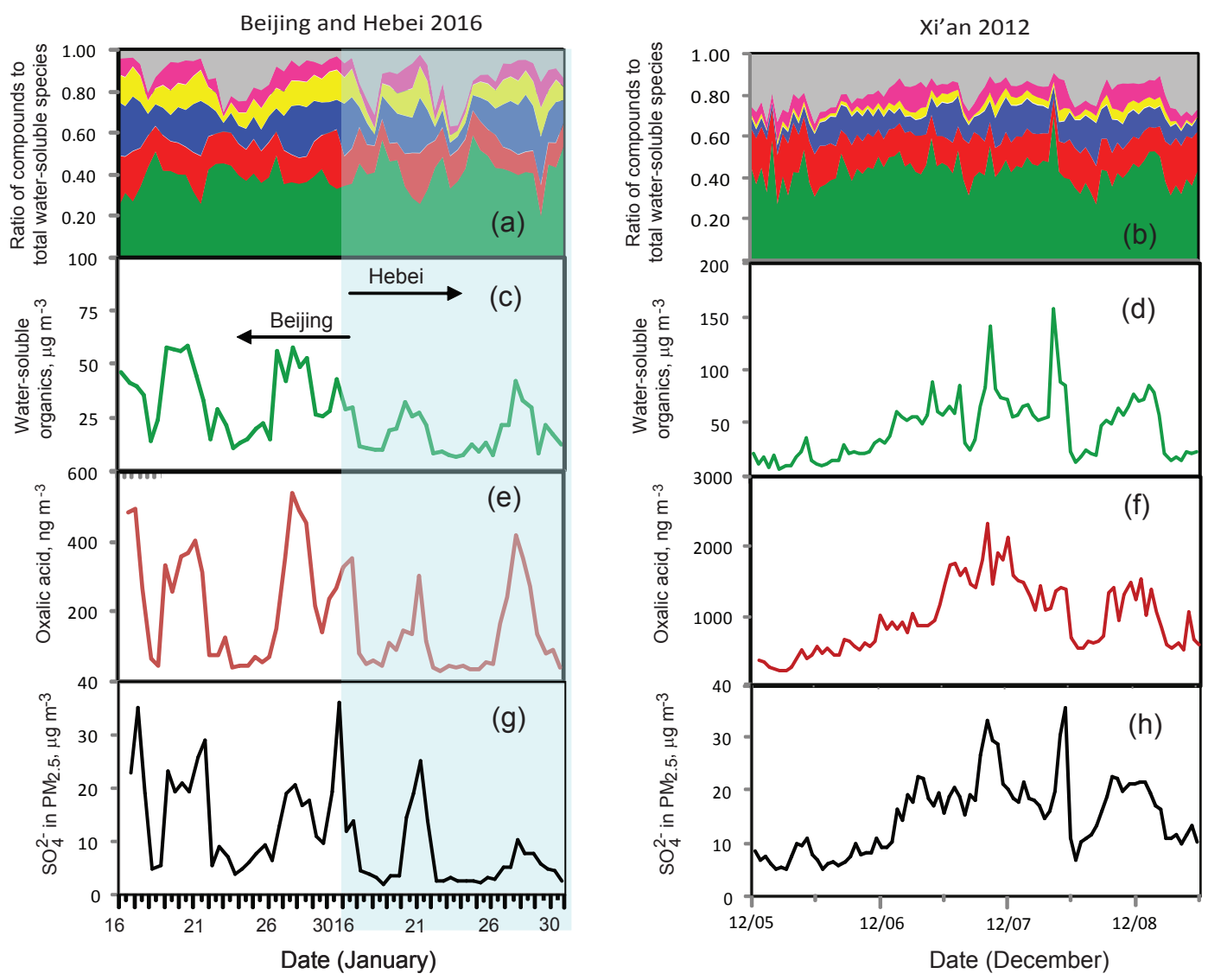

Figure 3. Measurements of water-soluble organic matter (WSOM) of $\mathrm{PM}_{2.5}$ collected in Beijing and Hebei Province during the winter of 2016 (a, c, e, g) and in Xi' an during the winter of $2012(\mathbf{b}, \mathbf{d}, \mathbf{f}, \mathbf{h})$. In panels (a) and (b), the green, red, blue, yellow, pink, and gray colors represent WSOM, sulfate, nitrate, ammonium, chloride, and the others (i.e., the sum of $\mathrm{Na}^{+}+\mathrm{Ca}^{2+}+\mathrm{Mg}^{2+}+\mathrm{K}^{+}$), respectively.

mass concentration of WSOM ranges from 10 to $60 \mu \mathrm{g} \mathrm{m} \mathrm{m}^{-3}$ in Beijing and Hebei Province during the winter of 2016 and from 10 to $180 \mathrm{\mu g} \mathrm{m}^{-3}$ in Xi' an during the winter of 2012 (Fig. 3c and d, respectively). Compared to those in Beijing and Hebei Province, the more abundant WSOM in Xi' an was caused by more emissions from biomass burning for house heating ( $\mathrm{Li}$ et al., 2016). As seen in Fig. 3c-f, the variation of WSOM displays a temporal pattern similar to that of oxalic acid, with a linear correlation coefficient of $0.79,0.88$ and 0.72 in Beijing, Hebei Province, and Xi' an, respectively (Fig. 3e and f). The mass concentration of oxalic acid in fine PM during the haze episodes is about $500 \mathrm{ng} \mathrm{m}^{-3}$ in Beijing and Hebei Province (Fig. 3e) and more than $2000 \mathrm{ng} \mathrm{m}^{-3}$ in Xi' an (Fig. 3f). Hence, our field measurements indicate that oxalic acid represents one of the most abundant WSOM in the aerosol-phase. Oxalic acid is a secondary product formed from the aqueous-phase oxidation of water-soluble organic precursors and ubiquitously exists in the troposphere. Like other pollutants, oxalic acid has been also shown to occur in large abundance in China (Wang et al., 2012; Cheng et al., 2013; Meng et al., 2014; Kawamura and Bikkina, 2016).
As shown in Fig. 3g and h, during the field observation periods sulfate at the three sites showed a temporal variation pattern similar to that of oxalic acid with a robust linear correlation $\left(r^{2}=0.67,0.84\right.$ and 0.61 in Xi' an, Beijing and Hebei Province, respectively). Such a correlation was also reported by other researchers (Wang et al., 2017; Yu et al., 2005), suggesting the co-occurrence and internally mixing state of both compounds in the atmosphere. In addition, the previous field measurements also revealed that WSOM in China is not only enriched in carboxylic acids (including oxalic acid) but also in other organic species, including carbonyls, amines, and water-soluble nitrogen-containing organic compounds (G. Wang et al., 2010; Wang et al., 2013; Zheng et al., 2015; Yao et al., 2016; F. Liu et al., 2017). The dominant organic acids and bases indicate that haze particles in China are multi-component in nature and the estimations of the particle acidity (or $\mathrm{pH}$ ) and the sulfate production rate need to take into account of the effects of organic species, in addition to inorganic ions. 


\section{Discussion}

Several recent studies using thermodynamic models (Wexler and Clegg, 2002; Fountoukis and Nenes, 2007) estimated the particle acidity and sulfate production during pollution episodes in China (Cheng et al., 2016; Guo et al., 2017a; M. Liu et al., 2017). Those previous studies treated the PM exclusively as a mixture of inorganic salts dominated by ammonium sulfate and neglected the effects due to the presence of organic compounds. Apparently, the conclusions by those modeling studies hinge on the validity of several critical assumptions in their analyses, including the application of the thermodynamic model, the accuracy in determining the aerosol water content (AWC), and the applicability of the earlier experimental measurements for the aqueous oxidation of $\mathrm{SO}_{2}$ by $\mathrm{NO}_{2}$ to atmospheric conditions.

Estimation of the $\mathrm{pH}$ values using the thermodynamic models is typically of considerable uncertainty, because of several intricate difficulties. For example, the ISORRPIA-II model includes two modes, i.e., metastable (aerosols are assumed to be in the liquid-phase only and may reach supersaturation) and stable (aerosols are assumed in the liquidand solid phases that are in equilibrium) (Guo et al., 2017b). As the thermodynamic model is established on the basis of the equilibrium principles, its application to non-equilibrium conditions needs to be rigorously assessed. In addition, the phase (e.g., liquid, amorphous, or crystalline) and mixing state of ambient aerosols are highly complex because of the presence of multi-component organic and inorganic species (Qiu and Zhang, 2013; Zhang et al., 2015), inevitably rendering high uncertainty in the thermodynamic calculations.

Guo et al. (2017a) suggested that the $\mathrm{pH}$ predictions using the metastable mode would be more reliable than that using the stable mode, on the basis of model evaluation from measured and predicted $\mathrm{NO}_{3}^{-}$and $\mathrm{NH}_{4}^{+}$during the winter of 2012 in Xi'an. Figure 4 compares the concentrations of $\mathrm{NH}_{3}$ (g) and aerosol species predicted by ISORROPIA-II with the field measurements under the metastable and stable modes in $\mathrm{Xi}^{\prime}$ an during the winter of 2012. As evident in Fig. $4 \mathrm{a}$ and $\mathrm{b}, \mathrm{NH}_{3}$ predicted is similar to the measured value with the metastable or stable mode. Furthermore, the predicted concentrations of $\mathrm{NO}_{3}^{-}$and $\mathrm{NH}_{4}^{+}$using both the metastable and stable modes are nearly identical (Fig. $4 \mathrm{c}-\mathrm{f}$ ). Guo et al. (2017a) only compared the liquid $\mathrm{NH}_{4}^{+}$and $\mathrm{NO}_{3}^{-}$ predicted by the model under the stable mode with the field measured aerosols composed of both liquid and solid compounds, and thus their predicted concentrations were lower than those of the measurements (see Fig. S1 in Guo et al., 2017a). As a result, their statement that $\mathrm{pH}$ prediction with the metastable mode would be more reliable than that with the stable mode was unjustified. Noticeably, the $\mathrm{pH}$ values estimated by the ISORROPIA-II model under the two modes are significantly different, with the values of $4.57 \pm 0.40$ under the metastable mode and $6.96 \pm 1.33$ under the stable mode. Most recently, it was suggested that the large discrep- ancy in predicting $\mathrm{pH}$ is attributable to the model code errors (Song et al., 2018).

In addition, the $\mathrm{pH}$ estimation by the thermodynamic model is highly dependent on the ratio of the concentration of hydrogen ions in the liquid-phase to AWC. Guo et al. (2017a) and M. Liu et al. (2017) assumed negligible particle water associated with the organic aerosol mass. Such an assumption is clearly invalid, as aerosols typically contain a large portion of WSOM in China (Fig. 3), including organic nitrogen species (G. Wang et al., 2010; Wang et al., 2013) and acids (G. Wang et al., 2009, 2010; Wang et al., 2006). Also, organic acids engage in particle-phase reactions with the basic species (i.e., $\mathrm{NH}_{3}$ and amines), significantly enhancing the particle hygroscopicity and reducing the acidity (GomezHernandez et al., 2016). In addition, because of their strong basicity and high abundance, amines likely play a key role in reducing the particle acidity in China (L. Wang et al., 2010a, b; Qiu et al., 2011; Qiu and Zhang, 2012; Dong et al., 2013; Zheng et al., 2015; Yao et al., 2016; F. Liu et al., 2017). Consequently, the acidity for organics-dominated aerosols is considerably different from that of ammonium sulfate aerosols, as demonstrated in our experimental results. While effort has been made to account for the effects of organic species on the aerosol properties (Clegg et al., 2013), the available thermodynamic models are still inadequate in representing complex multi-component aerosols. An inconsistency of the ammonium-sulfate ratios using the thermodynamic models was identified in the eastern US, also suggesting a possible role for organic species (Silvern et al., 2017).

Furthermore, the chemical mechanism leading to the aqueous conversion of $\mathrm{SO}_{2}$ to sulfate by $\mathrm{NO}_{2}$ is not well understood. The previous modeling studies adopted the aqueous reaction rate constants previously measured (Lee and Schwartz, 1983; Clifton et al., 1988), while the applicability of the earlier experimental studies to atmospheric conditions is uncertain. For example, Lee and Schwartz (1983) examined the oxidation of $\mathrm{S}(\mathrm{IV})$ by $\mathrm{NO}_{2}$ in the liquid phase by flowing gaseous $\mathrm{NO}_{2}$ through a $\mathrm{NaHSO}_{3}$ solution at a constant $\mathrm{pH}$ by regulating $\mathrm{NaOH}$ and determined the rate constant of $1.4 \times 10^{5} \mathrm{M}^{-1} \mathrm{~s}^{-1}$ at $\mathrm{pH}=5$ and with a lower limit of $2 \times 10^{6} \mathrm{M}^{-1} \mathrm{~s}^{-1}$ at $\mathrm{pH}=5.8$ and 6.4 from measuring the electrical conductivity of the solution. Clifton et al. (1988) measured the rate constant for the reaction of $\mathrm{NO}_{2}$ with $\mathrm{S}(\mathrm{IV})$ over the $\mathrm{pH}$ range of 5.3-13, by producing $\mathrm{NO}_{2}$ from irradiation of $\mathrm{NaNO}_{2}$ and $\mathrm{N}_{2} \mathrm{O}$ solutions and mixing with $\mathrm{Na}_{2} \mathrm{SO}_{3}$ solutions, and obtained the second-order rate constant of $1.24 \times 10^{7}$ and $2.95 \times 10^{7} \mathrm{M}^{-1} \mathrm{~s}^{-1}$ from the decay of $\mathrm{NO}_{2}$ monitored by absorption spectroscopy. The results of the measured rate constants between the two earlier experimental measurements differed by 1-2 orders of magnitude (Lee and Schwartz, 1983; Clifton et al., 1988). Also, both kinetic experiments employed bulk solutions and did not account for the gaseous uptake process (Lee and Schwartz, 1983; Clifton et al., 1988). 

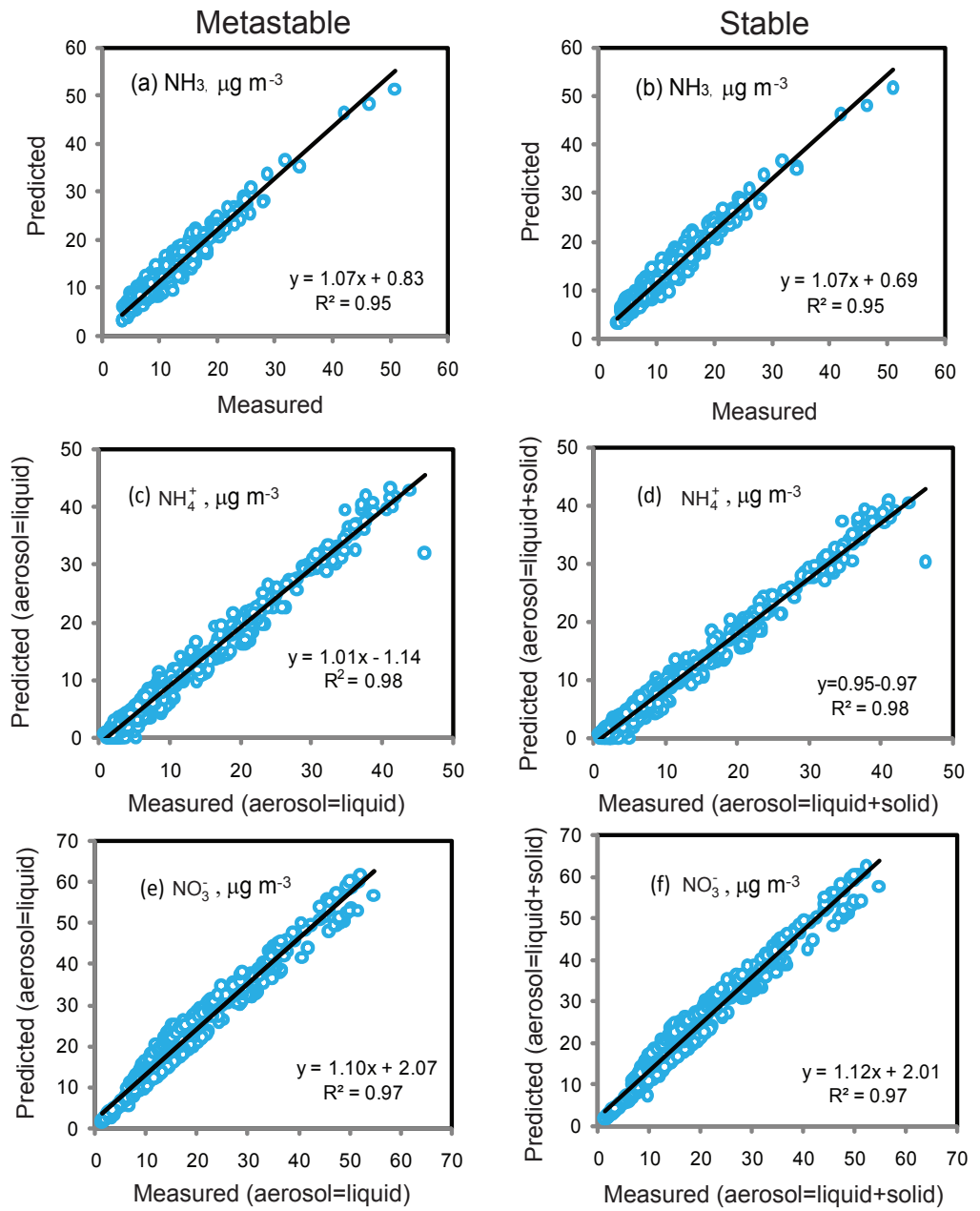

Figure 4. Comparison of measured $\mathrm{NH}_{3}, \mathrm{NH}_{4}^{+}$, and $\mathrm{NO}_{3}^{-}$concentrations with those predicted by ISORROPIA-II model using the forward mode under the metastable (a, c, e) and stable assumptions (b, d, f).

Wang et al. (2016) obtained the $\mathrm{SO}_{2}$ uptake coefficient for sulfate production from combined field measurements and laboratory experiments, and their laboratory experiments using aqueous oxalic acid particles reproduced the rapid sulfate production measured under polluted ambient conditions in China. The $\mathrm{SO}_{2}$ uptake coefficient on oxalic acid particles in the laboratory reaction chamber is $8.3 \pm 5.7 \times 10^{-5}$ (Wang et al., 2016) under the humid conditions and similar to that $\left(4.5 \pm 1.1 \times 10^{-5}\right)$ (Wang et al., 2016) observed in Beijing during the haze period of 2015. The results of the $\mathrm{SO}_{2}$ uptake coefficients determined by Wang et al. (2016) are also consistent with the modeling studies in quantification of the sulfate formation using atmospheric models in the country (e.g., Wang et al., 2014), indicating the applicability of their proposed mechanism to haze conditions in China. In contrast, M. Liu et al. (2017) invoked the experimental work by Hung and Hoffmann (2015) as a plausible cause for rapid $\mathrm{SO}_{2}$ oxidation by $\mathrm{O}_{2}$ in the absence of photochemistry, but without noting the high acidity as a necessary condition in that experimental work (i.e., $\mathrm{pH} \leq 3$ ). Most recently, $\mathrm{Li}$ et al. (2018) suggested an indirect mechanism of $\mathrm{SO}_{2}$ oxidation by $\mathrm{NO}_{2}$ via $\mathrm{HONO} / \mathrm{NO}_{2}^{-}$produced in fast-hydrolytic disproportion of $\mathrm{NO}_{2}$ on the surface of $\mathrm{NaHSO}_{3}$ aqueous microjets. In addition, another recent theoretical work by Zhang et al. (2018) indicated that under weakly acidic and neutral conditions $(\mathrm{pH} \leq 7)$ the oxidation of $\mathrm{HOSO}_{2}^{-}$by dissolved $\mathrm{NO}_{2}$ is a self-sustaining process, where the produced cis-HONO, $\mathrm{HSO}_{4}^{-}$, and $\mathrm{H}_{2} \mathrm{SO}_{4}$ promote the tautomerization from $\mathrm{HSO}_{3}^{-}$ to $\mathrm{HOSO}_{2}^{-}$as the catalysts.

\section{Conclusions}

In this paper we have presented experimental measurements of the growth of ammonium sulfate seed particles exposed to vapors of $\mathrm{SO}_{2}, \mathrm{NO}_{2}$, and $\mathrm{NH}_{3}$ at variable $\mathrm{RH}$, the $\mathrm{HGF}$ of oxalic acid particles, and field measurements of WSOM for $\mathrm{PM}_{2.5}$ during the severe haze events in Beijing, Hebei Province, and Xi' an. Our experimental results reveal that sul- 
fate production on fine particles is dependent on the particle hygroscopicity, phase-state, and acidity, as well as RH. The acidity and sulfate formation for ammonium sulfate seed particles are distinct from those of oxalic acid seed particles. Aqueous ammonium sulfate particles show negligible growth because of low $\mathrm{pH}$, in contrast to aqueous oxalic acid particles with significant dry-size increase and sulfate formation because of high $\mathrm{pH}$. In addition, our atmospheric measurements show significant concentrations of WSOM (including oxalic acid) in fine PM, indicating multi-component haze particles in China. Our results reveal that a particle mixture of inorganic salts adopted by the previous studies using the thermodynamic model does not represent a suitable model system and that the particle acidity and aqueous sulfate formation rate cannot be reliably inferred without accounting for the effects of multi-chemical compositions during severe haze events in China. Our combined experimental and field measurements corroborate the earlier finding that sulfate production via the particle-phase reaction involving $\mathrm{SO}_{2}$ and $\mathrm{NO}_{2}$ with $\mathrm{NH}_{3}$ neutralization occurs efficiently on organics-dominated aerosols (Wang et al., 2016) but are in contradiction to the most recent studies using the thermodynamic model (Guo et al., 2017a; M. Liu et al., 2017).

In conclusion, while the particle acidity or $\mathrm{pH}$ cannot be accurately determined from atmospheric field measurements or calculated using the thermodynamic models, our combined experimental and field results provide the compelling evidence that the $\mathrm{pH}$ value of ambient organics-dominated particles is sufficiently high to promote $\mathrm{SO}_{2}$ oxidation by $\mathrm{NO}_{2}$ with $\mathrm{NH}_{3}$ neutralization under polluted conditions in China.

Data availability. The field observational and the lab experimental data used in this study are available from the corresponding author upon request (Gehui Wang via ghwang@geo.ecnu.edu.cn, or wanggh@ieecas.cn).

Author contributions. GW and RZ designed the research; GW, FZ, JP, LD, YJ, WMO, JW, JL, CW, CC, YuaW, JZ, JS, YL, YuyW, HL, NL, and RZ performed the experimental work. GW and RZ analyzed the data; GW and RZ wrote the paper.

Competing interests. The authors declare that they have no conflict of interest.

Special issue statement. This article is part of the special issue "Regional transport and transformation of air pollution in eastern China”. It is not associated with a conference.

Acknowledgements. Financial support for this work was provided by National Key R\&D Plan (Quantitative Relationship and Regulation Principle between Regional Oxidation Capacity of Atmospheric and Air Quality; no. 2017YFC0210000), the China National Natural Science Funds for Distinguished Young Scholars (no. 41325014), a program from the National Nature Science Foundation of China (no. 41773117). This work was also supported by the Robert A. Welch Foundation (grant A-1417). Wilmarie Marrero-Ortiz was supported by the National Science Foundation Graduate Research Fellowship Program.

Edited by: Zhanqing Li

Reviewed by: two anonymous referees

\section{References}

Cheng, C., Wang, G., Zhou, B., Meng, J., Li, J., Cao, J., and Xiao, S.: Comparison of dicarboxylic acids and related compounds in aerosol samples collected in Xi' an, China during haze and clean periods, Atmos. Environ., 81, 443-449, 2013.

Cheng, C., Wang, G., Meng, J., Wang, Q., Cao, J., Li, J., and Wang, J.: Size-resolved airborne particulate oxalic and related secondary organic aerosol species in the urban atmosphere of Chengdu, China, Atmos. Res., 161-162, 134-142, 2015.

Cheng, Y., Zheng, G., Wei, C., Mu, Q., Bo Zheng, Wang, Z., Gao, M., Zhang, Q., He, K., Carmichae, G., Pöschl, U., and Su, H.: Reactive nitrogen chemistry in aerosol water as a source of sulfate during haze events in China, Science Advances, 2, e1601530, https://doi.org/10.1126/sciadv.1601530, 2016.

Clegg, S. L., Qiu, C., and Zhang, R.: The deliquescence behaviour, solubilities, and densities of aqueous solutions of five methyland ethyl-aminium sulphate salts, Atmos. Environ., 73, 1-14, 2013.

Clifton, C. L., Altstein, N., and Huie, R. E.: Rate constant for the reaction of nitrogen dioxide with sulfur(IV) over the $\mathrm{pH}$ range 5.3-13, Environ. Sci. Technol., 22, 586-589, 1988.

Dong, X. L., Liu, D. M., and Gao, S. P.: Seasonal variations of atmospheric heterocyclic aromatic amines in Beijing, China, Atmos. Res., 120, 287-297, 2013.

Fountoukis, C. and Nenes, A.: ISORROPIA II: a computationally efficient thermodynamic equilibrium model for $\mathrm{K}^{+}-$ $\mathrm{Ca}^{2+}-\mathrm{Mg}^{2+}-\mathrm{NH}_{4}^{+}-\mathrm{Na}^{+}-\mathrm{SO}_{4}^{2-}-\mathrm{NO}_{3}^{-}-\mathrm{Cl}^{-}-\mathrm{H}_{2} \mathrm{O}$ aerosols, Atmos. Chem. Phys., 7, 4639-4659, https://doi.org/10.5194/acp-74639-2007, 2007.

Gomez-Hernandez, M., McKeown, M., Secrest, J., Marrero-Ortiz, W., Lavi, A., Rudich, Y., Collins, D. R., and Zhang, R.: Hygroscopic characteristics of alkylaminium carboxylate Aerosols, Environ. Sci. Technol., 50, 2292-2300, 2016.

Guo, H., Weber, R. J., and Nenes, A.: High levels of ammonia do not raise fine particle $\mathrm{pH}$ sufficiently to yield nitrogen oxide-dominated sulfate production, Sci. Rep., 7, 12109, https://doi.org/10.1038/s41598-017-11704-0, 2017a.

Guo, H., Liu, J., Froyd, K. D., Roberts, J. M., Veres, P. R., Hayes, P. L., Jimenez, J. L., Nenes, A., and Weber, R. J.: Fine particle $\mathrm{pH}$ and gas-particle phase partitioning of inorganic species in Pasadena, California, during the 2010 CalNex campaign, Atmos. Chem. Phys., 17, 5703-5719, https://doi.org/10.5194/acp17-5703-2017, 2017b.

Guo, S., Hu, M., Zamora, M. L., Peng, J. F., Shang, D. J., Zheng, J., Du, Z. F., Wu, Z., Shao, M., Zeng, L. M., Molina, M. J., and 
Zhang, R. Y.: Elucidating severe urban haze formation in China, P. Natl. Acad. Sci. USA, 111, 17373-17378, 2014.

Hung, H.-M. and Hoffmann, M. R.: Oxidation of gas-phase SO2 on the surfaces of acidic microdroplets: Implications for sulfate and sulfate radical anion formation in the atmospheric liquid phase, Environ. Sci. Technol., 49, 13768-13776, 2015.

Kawamura, K. and Bikkina, S.: A review of dicarboxylic acids and related compounds in atmospheric aerosols: Molecular distributions, sources and transformation, Atmos. Res., 170, 140-160, 2016.

Khalizov, A. F., Zhang, R., Zhang, D. Xue, H., Pagels, J., and McMurry, P. H.: Formation of highly hygroscopic aerosols upon internal mixing of airborne soot particles with sulfuric acid vapor, J. Geophys. Res.-Atmos., 114, D05208, https://doi.org/10.1029/2008JD010595, 2009.

Lee, Y. N. and Schwartz, S. E.: Kinetics of oxidation of aqueous sulfur (IV) by nitrogen dioxide, in: Precipitation scavenging, dry deposition, and resuspension, edited by: Pruppacher, H. R., Semmon, R. G., and Slinm, W. G. N., Elsevier, New York, USA, 1983.

Li, J., Wang, G., Ren, Y., Wang, J., Wu, C., Han, Y., Zhang, L., Cheng, C., and Meng, J.: Identification of chemical compositions and sources of atmospheric aerosols in Xi' an, inland China during two types of haze events, Sci. Total Environ., 566-567, 230 237, 2016

Li, L., Hoffmann, M. R., and Colussi, A. J.: The role of nitrogen dioxide in the production of sulfate during Chinese haze-aerosol episodes, Environ. Sci. Technol., 52, 2686-2693, https://doi.org/10.1021/acs.est.7b05222, 2018.

Liu, F., Bi, X., Zhang, G., Peng, L., Lian, X., Lu, H., Fu, Y., Wang, X., Peng, P. a., and Sheng, G.: Concentration, size distribution and dry deposition of amines in atmospheric particles of urban Guangzhou, China, Atmos. Environ., 171, 279-288, 2017.

Liu, M., Song, Y., Zhou, T., Xu, Z., Yan, C., Zheng, M., Wu, Z., $\mathrm{Hu}, \mathrm{M} ., \mathrm{Wu}, \mathrm{Y}$., and Zhu, T.: Fine particle $\mathrm{pH}$ during severe haze episodes in Northern China, Geophys. Res. Lett., 44, 5213-5221, https://doi.org/10.1002/2017GL073210, 2017.

Meng, J., Wang, G., Li, J., Cheng, C., Ren, Y., Huang, Y., Cheng, Y., Cao, J., and Zhang, T.: Seasonal characteristics of oxalic acid and related SOA in the free troposphere of Mt. Hua, central China: Implications for sources and formation mechanisms, Sci. Total Environ., 493, 1088-1097, 2014.

Mikhailov, E., Vlasenko, S., Martin, S. T., Koop, T., and Pöschl, U.: Amorphous and crystalline aerosol particles interacting with water vapor: conceptual framework and experimental evidence for restructuring, phase transitions and kinetic limitations, Atmos. Chem. Phys., 9, 9491-9522, https://doi.org/10.5194/acp-9-94912009, 2009.

Pagels, J., McMurry, P. H., Khalizov, A. F., and Zhang, R.: Processing of soot by controlled sulphuric acid and water condensation Mass and mobility relationship, Aerosol Sci. Tech., 43, 629-640, 2009.

Peng, C., Chan, M. N., and Chan, C. K.: The hygroscopic properties of dicarboxylic and multifunctional acids: measurements and UNIFAC predictions, Environ. Sci. Technol., 35, 4495-4501, 2001.

Peng, J., Hu, M., Guo, S., Du, Z., Zheng, J., Shang, D., Zamora, M. L., Zeng, L., Shao, M., Wu, Y., Zheng, J., Wang, Y., Glen, C. R., Collins, D. R., Molina, M. J., and Zhang, R.: Markedly enhanced absorption and direct radiative forcing of black carbon under polluted urban environments, P. Natl. Acad. Sci. USA, 113, 4266-4271, 2016.

Prenni, A. J., DeMott, P. J., Kreidenweis, S. M., Sherman, D. E., Russell, L. M., and Ming, Y.: The effects of low molecular weight dicarboxylic acids on cloud formation, J. Phys. Chem. A, 105, 11240-11248, 2001.

Qiu, C. and Zhang, R.: Physiochemical Properties of Alkylaminium Sulfates: Hygroscopicity, Thermostability, and Density, Environ. Sci. Technol., 46, 4474-4480, 2012.

Qiu, C. and Zhang, R. Y.: Multiphase chemistry of atmospheric amines, Phys. Chem. Chem. Phys., 15, 5738-5752, 2013.

Qiu, Q., Wang, L., Lal, V., Khalizov, A. F., and Zhang, R.: Heterogeneous chemistry of Alkylamines on Ammonium Sulfate and Ammonium Bisulfate, Environ. Sci. Technol., 45, 4748-4755, 2011.

Seinfeld, J. H. and Pandis, S. N.: Atmospheric Chemistry and Physics: From Air Pollution to Climate Change, 2nd ed., John Wiley \& Sons, Hoboken, NJ, USA, 2006.

Silvern, R. F., Jacob, D. J., Kim, P. S., Marais, E. A., Turner, J. R., Campuzano-Jost, P., and Jimenez, J. L.: Inconsistency of ammonium-sulfate aerosol ratios with thermodynamic models in the eastern US: a possible role of organic aerosol, Atmos. Chem. Phys., 17, 5107-5118, https://doi.org/10.5194/acp17-5107-2017, 2017.

Song, S., Gao, M., Xu, W., Shao, J., Shi, G., Wang, S., Wang, Y., Sun, Y., and McElroy, M. B.: Fine-particle $\mathrm{pH}$ for Beijing winter haze as inferred from different thermodynamic equilibrium models, Atmos. Chem. Phys., 18, 7423-7438, https://doi.org/10.5194/acp-18-7423-2018, 2018.

Sun, Y. L., Wang, Z. F., Fu, P. Q., Yang, T., Jiang, Q., Dong, H. B., Li, J., and Jia, J. J.: Aerosol composition, sources and processes during wintertime in Beijing, China, Atmos. Chem. Phys., 13, 4577-4592, https://doi.org/10.5194/acp-13-4577-2013, 2013.

Wang, G., Kawamura, K., Umemoto, N., Xie, M., Hu, S., and Wang, Z.: Water-soluble organic compounds in $\mathrm{PM}_{2.5}$ and size-segregated aerosols over Mt. Tai in North China Plain, J. Geophys. Res.-Atmos., 114, D19208, dio.19210.11029/12008JD011390, 2009.

Wang, G., Xie, M., Hu, S., Gao, S., Tachibana, E., and Kawamura, K.: Dicarboxylic acids, metals and isotopic compositions of $\mathrm{C}$ and $\mathrm{N}$ in atmospheric aerosols from inland China: implications for dust and coal burning emission and secondary aerosol formation, Atmos. Chem. Phys., 10, 6087-6096, https://doi.org/10.5194/acp-10-6087-2010, 2010.

Wang, G., Kawamura, K., Cao, J., Zhang, R., Cheng, C., Li, J., Zhang, T., Liu, S., and Zhao, Z.: Molecular distribution and stable carbon isotopic composition of dicarboxylic acids, ketocarboxylic acids and a-dicarbonyls in size-resolved atmospheric particles from Xi'an city, China, Environ. Sci. Technol., 46, 4783-4791, 2012.

Wang, G., Zhang, R., Zamora, M. L., Gomez, M. E., Yang, L., Hu, M., Lin, Y., Guo, S., Meng, J., Li, J., Cheng, C., Hu, T., Ren, Y., Wang, Y., Gao, J., Cao, J., An, Z., Zhou, W., Wang, J., Marrero-Ortiz, W., Tian, P., Secrest, J., Peng, J., Du, Z., Zheng, J., Shang, D., Zeng, L., Shao, M., Wang, W., Huang, Y., Wang, Y., Zhu, Y., Li, Y., Hu, J., Pan, B., Cai, L., Cheng, Y., Rosenfeld, D., Liss, P. S., Duce, R. A., Kolb, C. E., and Molina, M. J.: Persistent Sulfate Formation from London Fog 
to Chinese Haze, P. Natl. Acad. Sci. USA, 113, 13630-13635, doi/13610.11073/pnas.1616540113, 2016.

Wang, G. H., Niu, S. L., Liu, C., and Wang, L. S.: Identification of dicarboxylic acids and aldehydes of $\mathrm{PM}_{10}$ and $\mathrm{PM}_{2.5}$ aerosols in Nanjing, China, Atmos. Environ., 36, 1941-1950, 2002.

Wang, G. H., Kawamura, K., Watanabe, T., Lee, S. C., Ho, K. F., and Cao, J. J.: Heavy loadings and source strengths of organic aerosols in China, Geophys. Res. Lett., 33, L22801, https://doi.org/10.1029/2006GL027624, 2006.

Wang, G. H., Zhou, B. H., Cheng, C. L., Cao, J. J., Li, J. J., Meng, J. J., Tao, J., Zhang, R. J., and Fu, P. Q.: Impact of Gobi desert dust on aerosol chemistry of Xi' an, inland China during spring 2009: differences in composition and size distribution between the urban ground surface and the mountain atmosphere, Atmos. Chem. Phys., 13, 819-835, https://doi.org/10.5194/acp-13-8192013, 2013.

Wang, J., Wang, G., Gao, J., Wang, H., Ren, Y., Li, J., Zhou, B., Wu, C., Zhang, L., Wang, S., and Chai, F.: Concentrations and stable carbon isotope compositions of oxalic acid and related SOA in Beijing before, during, and after the 2014 APEC, Atmos. Chem. Phys., 17, 981-992, https://doi.org/10.5194/acp-17981-2017, 2017.

Wang, L., Lal, V., Khalizov, A. F., and Zhang, R.: Heterogeneous chemistry of alkylamines with sulfuric acid: Implications for atmospheric formation of alkylaminium sulfates, Environ. Sci. Technol., 44, 2461-2465, 2010a.

Wang, L., Khalizov, A.F., Zheng, J., Xu, W., Lal, V., Ma, Y., and Zhang, R.: Atmospheric nanoparticles formed from heterogeneous reactions of organics, Nat. Geosci., 3, 238-242, $2010 \mathrm{~b}$.

Wang, Y., Zhang, Q., Jiang, J., Zhou, W., Wang, B., He, K., Duan, F., Zhan, Q., Philip, S., and Xie, Y.: Enhanced sulfate formation during China's severe winter haze episode in January 2013 missing from current models, J. Geophys. Res.-Atmos., 119, 1042510440, https://doi.org/10.1002/2013JD021426, 2014.
Wexler, A. S. and Clegg, S. L.: Atmospheric aerosol models for systems including the ions $\mathrm{H}^{+}, \mathrm{NH}_{4}^{+}, \mathrm{Na}^{+}, \mathrm{SO}_{4}^{2-}$, $\mathrm{NO}_{3}^{-}, \mathrm{Cl}^{-}, \mathrm{Br}^{-}$and $\mathrm{H}_{2} \mathrm{O}$, J. Geophys. Res., 107, 4207, https://doi.org/10.1029/2001JD000451, 2002.

Yao, L., Wang, M.-Y., Wang, X.-K., Liu, Y.-J., Chen, H.-F., Zheng, J., Nie, W., Ding, A.-J., Geng, F.-H., Wang, D.-F., Chen, J.-M., Worsnop, D. R., and Wang, L.: Detection of atmospheric gaseous amines and amides by a high-resolution timeof-flight chemical ionization mass spectrometer with protonated ethanol reagent ions, Atmos. Chem. Phys., 16, 14527-14543, https://doi.org/10.5194/acp-16-14527-2016, 2016.

Yu, J. Z., Huang, X. F., Xu, J. H., and Hu, M.: When aerosol sulfate goes up, so does oxalate: Implication for the formation mechanisms of oxalate, Environ. Sci. Technol., 39, 128-133, 2005.

Zhang, H., Chen, S., Zhong, J., Zhang, S., Zhang, Y., Zhang, X., Li, Z., and Zeng, X. C.: Formation of aqueous-phase sulfate during the haze period in China: Kinetics and atmospheric implications, Atmos. Environ., 177, 93-99, 2018.

Zhang, R., Wang, G., Guo, S., Zamora, M. L., Ying, Q., Lin, Y., Wang, W., Hu, M., and Wang, Y.: Formation of urban fine particulate matter, Chem. Rev., 115, 3803-3855, https://doi.org/10.1021/acs.chemrev.5b00067, 2015.

Zheng, J., Ma, Y., Chen, M., Zhang, Q., Wang, L., Khalizov, A. F., Yao, L., Wang, Z., Wang, X., and Chen, L.: Measurement of atmospheric amines and ammonia using the high resolution timeof-flight chemical ionization mass spectrometry, Atmos. Environ., 102, 249-259, 2015. 